\title{
An Empirical Case Study of DEMATEL Method Focus on Calculating the Students Organization Improvement in POLITALA
}

\author{
Titik Wijayati ${ }^{1, *}$, Mufrida Zein², Muhammad Ghalih ${ }^{3}$, Muhammad Fajar $^{4}$ \\ ${ }^{1}$ Departement of Information Engineering, Politeknik Negeri Tanah Laut, Indonesia \\ ${ }^{2,3}$ Departement of Economics and Business, Politeknik Negeri Tanah Laut, Indonesia \\ ${ }^{4}$ Department of Computer Science and Information Engineering, National Kaohsiung University of Science \\ and Technology, Taiwan
}

\begin{tabular}{l} 
Article Info \\
\hline Article history: \\
Received Oct 1, 2020 \\
Revised Feb 10, 2021 \\
Accepted April 25, 202 \\
\hline Keywords: \\
Calculating \\
DEMATEL \\
POLITALA \\
Improvement \\
Students Organization
\end{tabular}

\begin{abstract}
The single-mindedness of this study is to find the key factors prompting the Students Organization Improvement and explore the causal relationships between perspectives (P) and criteria (C). This case study used DecisionMaking Trial and Evaluation Laboratory (DEMATEL) method used for making decisions and analyses to forecast future scenarios. The results found that the DEMATEL include six main perspectives and eighteen criteria were extracted and then validated by fifteen experts. Therefore, the most critical evaluation perspective with the most exceptional value was 11.4074 , although Availability (P4) was the least essential perspective with the smallest value 7.0138. Regarding value, the prioritization of the importance of four evaluation perspectives numbered from perspectives P1 to perspectives P4. Finally, the proposed methods not only improve the DEMATEL methodology but also provide a valuable reference to do the best planning for Calculating the Students Organization Improvement in POLITALA.
\end{abstract}

This is an open access article under the $\underline{C C B Y-S A}$ license.

\section{Corresponding Author:}

Titik Wijayati,

Department of Information Engineering,

Politeknik Negeri Tanah Laut,

Jl. A. Yani Km.6, Panggung, Tanha Laut, South Kalimantan, Indonesia, 70815.

Email: wijayati_7670@politala.ac.id

\section{INTRODUCTION}

At the start of each semester, data from the student organization's list of activities for the academic year 2018-2019 was gathered. A spreadsheet was used to map many standards 3 and 4 to each chapter activity. Following completion, events that aligned with the organization's requirements were promoted via email and online sign-up sheets. Students who were active members of the chapter and involved in the organization were asked to take part in a survey. Multiple choice questions and statements with a 5-point Likert scale were included in the survey. Descriptive statistics were used to analyze the data. In POLITALA, on the other hand, the Students Organization has grown rapidly as a result of the numerous activities.

Unfortunately, it is ironic that a cross-sectional study design involved 4 Students Organization. Two statistical methodologies, hierarchical regression models and qualitative comparative analysis of diffuse sets, were used for data analysis. In the hierarchical regression models the number of students supervised predicted satisfaction with clinical educator $(\beta=-.22 ; \mathrm{p} \leq .001)$, environment $(\beta=-.13 ; \mathrm{p} \leq .05)$ and overall satisfaction $(\beta=-.15 ; p \leq .05)$. However, in the qualitative comparative analysis, the type of center, as well as the number of services assigned to the STEM educator and the number of students per STEM educator period were conditions that influence satisfaction with clinical practices. The type of center and the clinical educator are key factors related to registered nursing students' satisfaction with STEM practices. 
However, the purpose of this study was to find a justification that not only acknowledges the importance of DEMATEL methodologies to Students Organization, but also to provide approaches that can create a better understanding of the Students Organization in a more cost-effective and efficient manner. Furthermore, the research will aid in understanding the elements that influence profitability in the Students Organization, particularly in POLITALA.

\section{DEMATEL METHOD}

Explaining the DEMATEL (Decision-making trial and evaluation laboratory) technique, which was established by the Battelle Memorial Institute of Geneva's Science and Human Affairs Program [1]. Furthermore, by studying the unique problem [3], the cluster of the entangled problem [4], and identification of feasible solutions using a hierarchical structure [5];[6];[7], the DEMATEL aimed to research and address the intricate [2] and interconnected problem.

Many researchers have recently employed DEMATEL in many disciplines, such as Gandhi et al. introduced DEMATEL approach to analyze the relationships between the assessed components via a causal diagram. An empirical case study of an Indian manufacturing business was done to demonstrate the real-world applicability of the suggested DEMATEL-based methodology [8].

In the other study, however, Quader et al. adapted the 2-tuple DEMATEL approach, a Multi-criteria Decision Making (MCDM) tool, and the Delphi method by presenting a suitable environment to govern the cause-andeffect interactions among these criteria [9].

Furthermore, Tadi et al. demonstrated an unique hybrid MCDM model built [10] that incorporates fuzzy Decision Making Trial and Evaluation Laboratory Model (DEMATEL), fuzzy Analytical Network Process (ANP), and fuzzy (VIKOR) approaches.

In a separate study, George-Ufot et al. used a Fuzzy-DEMATEL model to examine the sustainable lifestyle factors of electricity consumption patterns in Nigeria, and proposed a method that integrates fuzzy logic and DEMATEL to evaluate sustainable lifestyle factors that influence industries' electric consumption patterns for the first time in Nigeria [11].

Shen et al., on the other hand, proposed a hybrid procedure involving economic and industrial possibilities as well as important technology streams toward a more active selection of new technology. The fuzzy Delphi approach, the DEMATEL technique, and the analytic network process (ANP) were combined to create a technology selection model for economic and industrial possibilities [12]. While Zhou et al. developed DDEMATEL as a combination of D number theory and DEMATEL to discover key success factors (CSFs) in emergency management [13].

In the other study, Rajesh and Ravi used a combination of Grey theory and DEMATEL techniques to determine cause and effect correlations among supply chain risk mitigation enablers [14]. Similarly, Song and Cao proposed an approach that integrates the strength of a group DEMATEL in measuring interaction relationships and the value of rough set theory in altering subjective judgements [15].

Furthermore, the DEMATEL approach was utilized in this work to create and analyze a structural model including causal interactions between complex elements [16] with the crucial factor in Students Organization. The DEMATEL was utilized to determine the interrelationships between the criteria [17]. In this study, fifteen experts were invited to fill out a questionnaire.

The DEMATEL was utilized to determine the interrelationships between the criteria. To address the extension of the DEMATEL methodology for decision making in the entirety of Organization Student the fundamentals of the standard DEMATEL techniques outlined below.

Stage 1: Establish measuring scales and allocate the trend and quantity of effect to variables. This stage comprises identifying and characterizing the different significant aspects of complex systems by the use of information gathered through literature research, expert opinions, or brainstorming. A degree of influence scale is also developed to do pairwise comparisons of the components and establish the causalities and degree of impact between them.

Stage 2: Authorize the use of a direct relationship matrix. After determining the significance of the measurement scales, a questionnaire survey approach is used. Experts use pairwise judgements of the components in this technique to estimate the degree and direction of interaction effect between elements. As a result, a direct connection matrix was developed. In this matrix, each value shows the magnitude of an interacting impact between components. The diagonal values in the matrix fixed as zero. 


$$
X=\left[\begin{array}{cccc}
0 & x_{12} & \cdots & x_{1 n} \\
x_{21} & 0 & \cdots & x_{2 n} \\
\vdots & \vdots & \ddots & \vdots \\
x_{n 1} & x_{n 2} & \cdots & 0
\end{array}\right]
$$

(1)

Stage 3: Calculate a normalized direct relation matrix, where the column vector and maximum value serve as normalization thresholds.

$$
\lambda=\frac{1}{\underset{1 \leq i \leq n}{\operatorname{Max}}\left(\sum_{j=1}^{n} x_{i j}\right)}
$$

$N=\lambda X$

Stage 4: Calculate the direct or indirect relation matrix $T$, likewise termed the total relation matrix.

$$
T=\lim _{k \rightarrow \infty}\left(N+N^{2}+\cdots+N^{k}\right)=N(I-N)^{-1}
$$

(3)

Stage 5: Determine the sum of the values in each column and each row. This step entails summing the values of each column and row in the total relation matrix, where $R_{i}$ is the sum of the $i^{\text {th }}$ row and $C_{j}$ is the sum of the $j^{\text {th }}$ column. The $R_{i}$ and $C_{j}$ values represent both the direct and indirect influences between factors.

$$
\begin{aligned}
& R_{i}=\sum_{j=1}^{n} t_{i j} \quad(i=1,2, \ldots, n) \\
& C_{j}=\sum_{i=1}^{n} t_{i j} \quad(j=1,2, \ldots, n)
\end{aligned}
$$

(5)

Stage 6: Stipulate the DEMATEL cause and effect diagram. Further, in this stage, $\left(R_{i}+C_{j}\right)$ is defined as notability and $k=i=j=1,2, \ldots, n$, illustrating the overall influential directions of a service attribute. This value indicates the core level of service attribute $k$ in question.

The parameter $\left(R_{i}-C_{j}\right)$ is distinct as a relation, demonstrating the difference in the influences of this service attribute. This value indicates the amount of the influence of the examination attribute $k$ in question; a positive value proposes that the character is a cause and a negative value suggests that the attribute is an effect. In the cause and effect figure, attributes are plotted on the horizontal axis according to the $\left(R_{i}+C_{j}\right)$ assessment and on the vertical axis conferring to the $\left(R_{i}-C_{j}\right)$ value. By using descriptions, complex causal relationships shortened into comprehensible visual structures.

Stage 7: A threshold is a value $(\alpha)$ computed by the average of the elements in matrix $T$, as calculated by equation (7). The calculation determines to eliminate some negligible effects elements in matrix $T$.

$$
\alpha=\frac{\sum_{i=1}^{n} \sum_{j=1}^{n}\left[t_{i j}\right]}{N}
$$

where $N$ is the total quantity of features in the matrix $T$.

Stage 8: Construct a cause and effect relationship illustration. The cause and effect diagram constructed by representing all coordinates sets $\left(R_{i}+C_{j}, R_{i}\right.$ - $\left.C_{j}\right)$ to visualize the complex interrelationship and afford evidence to judge which are the most important factors and how influence affected factors. The factors that more significant than $\alpha$, are selected shown in cause and effect diagram. 


\section{A CASE STUDY}

In In this circumstance, the study focuses on Organization Student, then the computation of the average matrix $A$ created by using equation (2) among Perspective (P) stage processes of applying DEMATEL method was shown following.

$$
\begin{aligned}
& A^{1}=\left(\begin{array}{llll}
0 & 2 & 4 & 4 \\
2 & 0 & 4 & 4 \\
4 & 4 & 0 & 1 \\
4 & 4 & 1 & 0
\end{array}\right) A^{2}=\left(\begin{array}{llll}
0 & 1 & 2 & 4 \\
1 & 0 & 0 & 0 \\
2 & 0 & 0 & 1 \\
4 & 1 & 1 & 0
\end{array}\right) A^{3}=\left(\begin{array}{llll}
0 & 2 & 2 & 4 \\
2 & 0 & 2 & 2 \\
4 & 2 & 0 & 1 \\
3 & 1 & 0 & 0
\end{array}\right) A^{4}=\left(\begin{array}{llll}
0 & 3 & 3 & 4 \\
2 & 0 & 3 & 1 \\
3 & 1 & 0 & 1 \\
4 & 1 & 0 & 0
\end{array}\right) \\
& A^{5}=\left(\begin{array}{llll}
0 & 4 & 4 & 4 \\
4 & 0 & 4 & 4 \\
4 & 4 & 0 & 4 \\
4 & 4 & 4 & 0
\end{array}\right) A^{6}=\left(\begin{array}{llll}
0 & 2 & 3 & 3 \\
4 & 0 & 3 & 1 \\
3 & 3 & 0 & 0 \\
1 & 0 & 0 & 0
\end{array}\right) A^{7}=\left(\begin{array}{llll}
0 & 3 & 2 & 3 \\
1 & 0 & 2 & 2 \\
3 & 3 & 0 & 0 \\
2 & 3 & 2 & 0
\end{array}\right) A^{8}=\left(\begin{array}{llll}
0 & 2 & 3 & 2 \\
4 & 0 & 2 & 2 \\
4 & 2 & 0 & 2 \\
2 & 2 & 2 & 0
\end{array}\right) \\
& A^{9}=\left(\begin{array}{llll}
0 & 4 & 1 & 4 \\
4 & 0 & 1 & 4 \\
4 & 1 & 0 & 4 \\
4 & 4 & 1 & 0
\end{array}\right) A^{10}=\left(\begin{array}{llll}
0 & 3 & 3 & 3 \\
3 & 0 & 3 & 3 \\
2 & 1 & 0 & 0 \\
4 & 1 & 0 & 0
\end{array}\right) A^{11}=\left(\begin{array}{llll}
0 & 4 & 2 & 4 \\
4 & 0 & 3 & 2 \\
2 & 4 & 0 & 4 \\
4 & 0 & 0 & 0
\end{array}\right) A^{12}=\left(\begin{array}{llll}
0 & 2 & 3 & 2 \\
3 & 0 & 2 & 3 \\
3 & 2 & 0 & 2 \\
2 & 3 & 2 & 0
\end{array}\right) \\
& A^{13}=\left(\begin{array}{llll}
0 & 2 & 3 & 3 \\
2 & 0 & 0 & 2 \\
0 & 3 & 0 & 1 \\
2 & 2 & 0 & 0
\end{array}\right) A^{14}=\left(\begin{array}{llll}
0 & 1 & 3 & 2 \\
1 & 0 & 2 & 1 \\
3 & 1 & 0 & 0 \\
3 & 1 & 1 & 0
\end{array}\right) A^{15}=\left(\begin{array}{llll}
0 & 3 & 3 & 3 \\
3 & 0 & 3 & 3 \\
0 & 3 & 0 & 1 \\
3 & 3 & 0 & 0
\end{array}\right)
\end{aligned}
$$

Then, this is the average matrix $A$ generated by using equation (2).

$$
A=\left(\begin{array}{rrrr}
0 & 2.53 & 2.73 & 3.26 \\
2.66 & 0 & 2.26 & 2.33 \\
2.73 & 2.26 & 0 & 1.46 \\
3.06 & 2 & 0.86 & 0
\end{array}\right)
$$

The normalized initial direct-relation matrix $N$ calculated by using equation (3).

$$
N=\left(\begin{array}{rrrr}
0 & 0.29 & 0.32 & 0.38 \\
0.31 & 0 & 0.26 & 0.27 \\
0.32 & 0.26 & 0 & 0.17 \\
0.35 & 0.23 & 0.10 & 0
\end{array}\right)
$$

The total relation matrix $T$ calculated by using equation (4) as presented below. 
47

International Journal of Research in Vocational Studies (IJRVOCAS)

$$
T=\left(\begin{array}{llll}
1.42 & 1.42 & 1.31 & 1.54 \\
1.50 & 1.07 & 1.16 & 1.34 \\
1.41 & 1.20 & 0.89 & 1.19 \\
1.36 & 1.12 & 0.93 & 0.99
\end{array}\right)
$$

The totalities of rows and columns of matrix $T$ calculated by using equation (5) to equation (6) the result of calculating the equations as shown below in Table 1 .

Table 1. Prominence and relation results

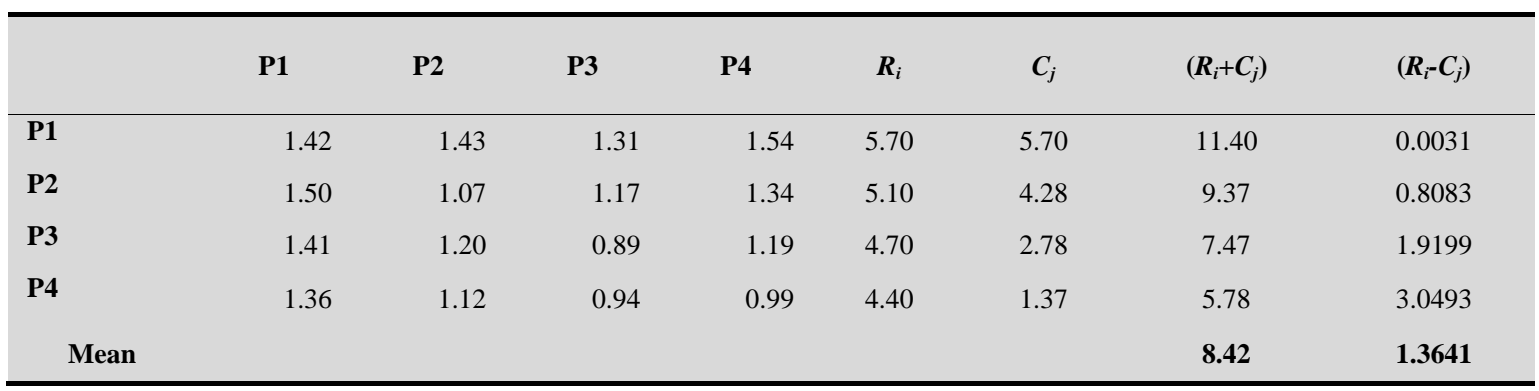

The threshold value $(\alpha)=2.1269$

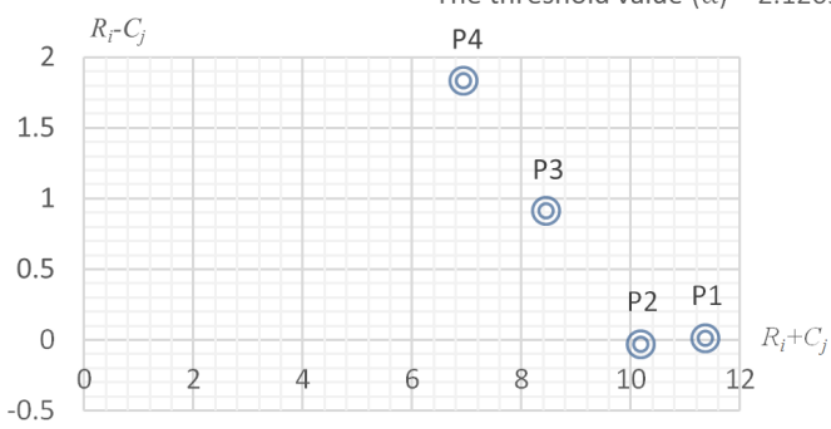

Figure 1. The causal relationship between the Perspective $(P)$

Table 2. The direct and indirect effects

\begin{tabular}{|c|c|c|}
\hline & $\left(R_{i}+C_{j}\right)$ & $\left(R_{i}+C_{j}\right)$ \\
\hline & \multicolumn{2}{|c|}{ Students Organization (P1) } \\
\hline Information Engginering (C1) & 5.68 & -0.16 \\
\hline Machine Otomotif (C2) & 5.55 & 0.01 \\
\hline Agroindustry (C3) & 4.83 & -0.27 \\
\hline \multirow[t]{2}{*}{ Accounting (C4) } & 4.21 & -0.58 \\
\hline & \multicolumn{2}{|c|}{ Personal Mastery (P2) } \\
\hline Action (C5) & 4.05 & -0.43 \\
\hline Endurance (C6) & 4.19 & 0.03 \\
\hline Attitude (C7) & 4.45 & 0.65 \\
\hline \multirow[t]{2}{*}{ Mindset (C8) } & 4.13 & 0.75 \\
\hline & \multicolumn{2}{|c|}{ Interpersonal Mastery (P3) } \\
\hline People Skill (C9) & 4.63 & 1.65 \\
\hline Communication (C10) & 2.92 & 0.42 \\
\hline \multirow[t]{2}{*}{ Trust (C11) } & 2.43 & 0.21 \\
\hline & \multicolumn{2}{|c|}{ Leadership Mastery (P4) } \\
\hline
\end{tabular}

An Empirical Case Study of DEMATEL Method Focus on Calculating the Students Organization Improvement in POLITALA 


\begin{tabular}{lll} 
Purpose (C12) & 2.16 & 0.22 \\
Servantship (C13) & 3.02 & 1.34 \\
Character (C14) & 2.72 & 1.41 \\
Competencies (C15) & 2.01 & 0.97 \\
Legacy (C16) & 2.05 & 1.30 \\
Influence (C17) & 1.58 & 1.13 \\
Teamwork (C18) & 1.37 & 1.17 \\
\hline
\end{tabular}

The cause and effect diagram of four perspectives as established in Figure 1. Based on the direct and indirect effects the eighteen criteria and four perspective cores stated in Table 2, this research has further employed the DEMATEL method to capture the complex relationships.

The threshold value $(\alpha)$ derived from the average of elements in matrix $T$, which considered by using equation (7). The importance of evaluation perspectives determined by $\left(R_{i}+C_{j}\right)$ values.

$$
\alpha=\frac{34.03}{16}=2.12
$$

The values of $t_{i j}$ in Table 2, which were less than $\alpha$ (2.12), which presented the interaction between perspectives, for instance, the value of $t_{i j}(1.42)<\alpha(2.12)$, the arrow in the cause and effect diagram drawn from $\mathrm{P} 1$ to $\mathrm{P} 2$.

Moreover, the consequences presented in the cause and effect diagram have apparently discovered the importance of Students Organization (P1) and Personal Mastery (P2). Those factors have correlated with the persistence of deciding Organization Student, while other two perspectives such as Interpersonal Mastery (P3) and Leadership Mastery (P4) have a minor impact in order make a decision making in Students Organization.

Under each Perspective (P), the critical criteria (C) determined by using the same procedures as described before. Together with direct and indirect effects of the criteria under four perspectives (P) summarized in Table 2 and the cause and effect diagrams between criteria under each perspective shown in Figure 2 . The entireties of rows and columns of matrix $T$ considered by using equation (5) to equation (6) the result of calculating the equations as shown below in Table 2 .

Furthermore, the importance of evaluation perspectives is resolute by values of the outcome. Based on Table 1, assume that Students Organization (P1) was the most critical evaluation perspective with the most significant value $=11.4074$, whereas Leadership Mastery (P4) was the least essential perspective with the smallest value $=7.0138$. Concerning a value, the prioritization of the importance of four evaluation perspective was $\mathrm{P} 1>\mathrm{P} 2>$ P3 $>$ P4.

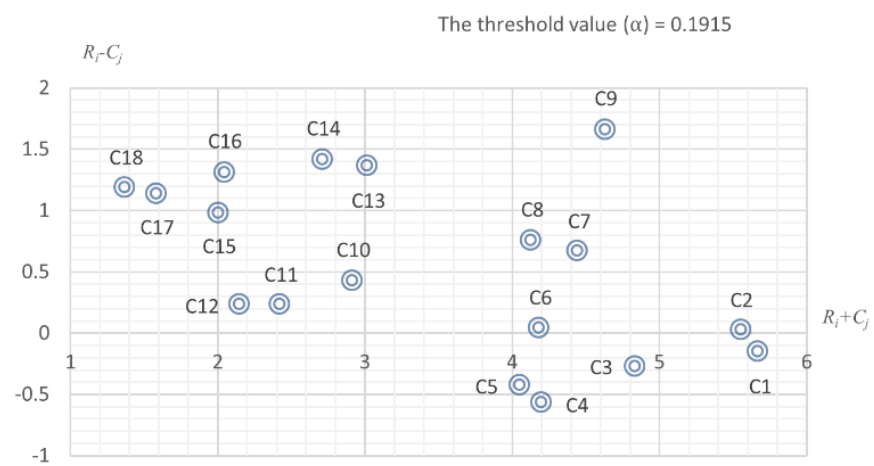

Figure 2. The causal relationship between the criteria $(C)$

\section{CONCLUSION (10 PT)}

By using DEMATEL method, the decision maker can categorize causal criteria (C) and perspectives (P) within each dimension and use the digraphs by understanding the relative cause-effect relationships between characteristics and perspectives. 
Therefore, in this study provides another perspective to implement Students Organization management without assuming characteristics and perspectives are mutually independent.

Truthfully, the decision maker can pay much attention and allocate resources to cause criteria (C) and perspectives (P) to efficiently implement Students Organization to calculate the Students Organization.

It remains indefinite whether these Students Organization study approaches are suitable for a different country with different sizes and different physical and climatic characteristics. Likewise, more research products could be developed to express the predictive uncertainty. Finally, as for the future study, inference rules must be including many aspects to make a make a decision-making method.

\section{ACKNOWLEDGEMENTS}

This research sponsored by Politeknik Negeri Tanah Laut. Also, this study supported by the Ministry of Research, Technology and Higher Education of the Republic of Indonesia.

\section{REFERENCES}

[1] H.-H. Wu and S.-Y. Chang, "A case study of using DEMATEL method to identify critical factors in green supply chain management," Appl. Math. Comput., vol. 256, pp. 394-403, 2015.

[2] Z. C. Lin, G. E. Hong, and P. F. Cheng, "A study of patent analysis of LED bicycle light by using modified DEMATEL and life span,” Adv. Eng. Informatics, vol. 34, pp. 136-151, 2017.

[3] T. Ghaemi Rad, A. Sadeghi-Niaraki, A. Abbasi, and S. M. Choi, "A methodological framework for assessment of ubiquitous cities using ANP and DEMATEL methods," Sustain. Cities Soc., vol. 37, no. July 2017, pp. 608-618, 2018.

[4] Y. Li and K. Mathiyazhagan, "Application of DEMATEL approach to identify the influential indicators towards sustainable supply chain adoption in the auto components manufacturing sector," J. Clean. Prod., vol. 172, pp. 2931-2941, 2016.

[5] U. Asan, C. Kadaifci, E. Bozdag, A. Soyer, and S. Serdarasan, “A New Approach to DEMATEL Based on IntervalValued Hesitant Fuzzy Sets,” Appl. Soft Comput., vol. 66, pp. 34-49, 2018.

[6] A. Kumar and G. Dixit, "An analysis of barriers affecting the implementation of e-waste management practices in India: A novel ISM-DEMATEL approach,” Sustain. Prod. Consum., vol. 14, pp. 36-52, 2018.

[7] X. Xia, K. Govindan, and Q. Zhu, "Analyzing internal barriers for automotive parts remanufacturers in China using grey-DEMATEL approach,” J. Clean. Prod., 2015.

[8] S. Gandhi, S. K. Mangla, P. Kumar, and D. Kumar, Evaluating factors in implementation of successful green supply chain management using DEMATEL: A case study, vol. 3, no. 1-2. Holy Spirit University of Kaslik, 2015.

[9] M. A. Quader, S. Ahmed, R. A. Raja Ghazilla, S. Ahmed, and M. Dahari, "Evaluation of criteria for CO2 capture and storage in the iron and steel industry using the 2-tuple DEMATEL technique," J. Clean. Prod., vol. 120, pp. $207-220,2015$.

[10] S. Tadić, S. Zečević, and M. Krstić, “A novel hybrid MCDM model based on fuzzy DEMATEL, fuzzy ANP and fuzzy VIKOR for city logistics concept selection,” Expert Syst. Appl., vol. 41, no. 18, pp. 8112-8128, 2014.

[11] G. George-Ufot, Y. Qu, and I. J. Orji, “Sustainable lifestyle factors influencing industries' electric consumption patterns using Fuzzy logic and DEMATEL: The Nigerian perspective,” J. Clean. Prod., vol. 162, pp. 624-634, 2017.

[12] Y. C. Shen, G. T. R. Lin, and G. H. Tzeng, "Combined DEMATEL techniques with novel MCDM for the organic light emitting diode technology selection,” Expert Syst. Appl., vol. 38, no. 3, pp. 1468-1481, 2011.

[13] X. Zhou, Y. Shi, X. Deng, and Y. Deng, "D-DEMATEL: A new method to identify critical success factors in emergency management,” Saf. Sci., vol. 91, pp. 93-104, 2017.

[14] R. Rajesh and V. Ravi, "Modeling enablers of supply chain risk mitigation in electronic supply chains: A GreyDEMATEL approach,” Comput. Ind. Eng., vol. 87, pp. 126-139, 2015.

An Empirical Case Study of DEMATEL Method Focus on Calculating the Students Organization Improvement in POLITALA 
DOI: https://doi.org/10.53893/ijrvocas.vli1.39

[15] W. Song and J. Cao, "A rough DEMATEL-based approach for evaluating interaction between requirements of product-service system,” Comput. Ind. Eng., vol. 110, pp. 353-363, 2017.

[16] S. Baruah, S. Raj, M. Shabbiruddin, A. Ray, and S. Chakravorty, "Analysis of influencing factors for costs on substation siting based on DEMATEL method,” Procedia Eng., vol. 38, pp. 2564-2571, 2012.

[17] S. Sarkar, D. K. Pratihar, and B. Sarkar, "An integrated fuzzy multiple criteria supplier selection approach and its application in a welding company,” J. Manuf. Syst., vol. 46, pp. 163-178, 2018.

\section{BIOGRAPHIES OF AUTHORS}
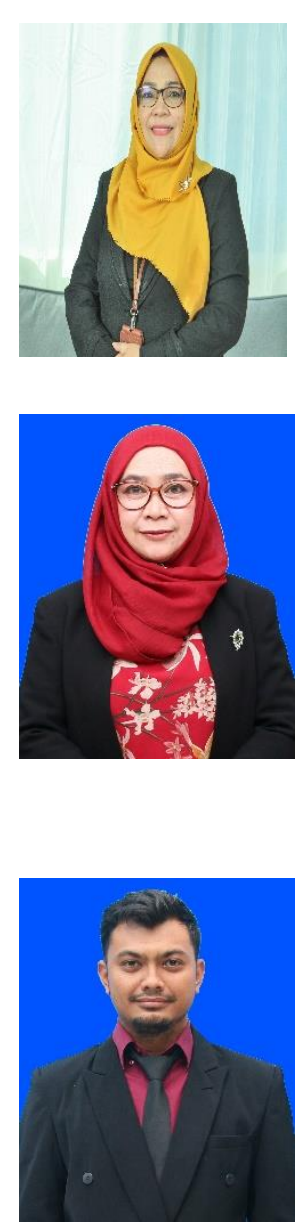

Muhammad Ghalih is a lecturer and researcher in the Accounting Department at Politeknik Negeri Tanah Laut. His research interests are in the area of International Business, Business Process Management, Product Development, E-Commerce and Marketing. He received his bachelor's degree in Science Communication (Public Relations) from Lambung Mangkurat University (2014). He holds a master's degree in International Business from National Kaohsiung University of Science and Technology (2018). He is also a Head of Office Internantional Affairs and the CEO of Ghalih Foundation.

Email: ghalih@politala.ac.id

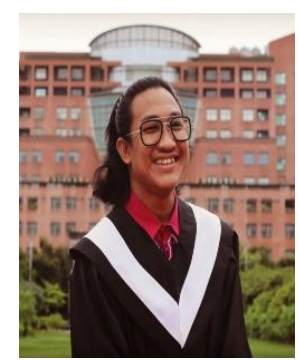

Muhammad Fajar completed Diploma III at Politeknik Negeri Tanah Laut and bachelor's Program (S1) at Kun Shan University then continue to Master (S2) at Department of Computer Science and Information Engineering, National Kaohsiung University of Science and Technology, Taiwan. Email: $\underline{\text { f110151131@nkust.edu.tw }}$ 